\title{
Carcinoma de los ductos colectores de Bellini: Presentación de un caso clínico y revisión del diagnóstico diferencial
}

\author{
C. Sebastián', C. Giménez', V. Pérez², I. Marquina², C. Ospina', A. Castán'.
}

1. Hospital MAZ de Zaragoza, Zaragoza - España.

2. Hospital Universitario Miguel Servet de Zaragoza, Zaragosa - España.

\section{Collecting (Bellini) duct carcinoma: A case presentation}

\begin{abstract}
Collecting (Bellini) duct carcinoma $(C D C)$ is a rare and very aggressive variant of renal cell carcinoma. Objectives: To describe the radiological findings of a CDC case and to determine its differential diagnosis. Basic procedures: Review the published works regarding this tumor and compare the radiological findings of our case with those of other described cases. Most important findings: CDCs are well-defined tumors with a high hemorrhagic component, limited internal enhancement and nodal metastases. In the differential diagnosis, if the lesion presents an exophytic growth it should include papillary carcinoma, mainly the sarcomatoid variant and the complex benign lesions (complex cysts or hydatids). However, if the lesion combines an infiltrating pattern, other lesions such as medullary carcinoma or lymphoma will be taken into account. Main conclusions: In the presence of solid-cystic hypovascular lesions and regional lymphadenopathy, CDC must be included in the differential diagnosis. Key words: Bellini duct carcinoma; Renal tumor; Differential diagnosis; MRI; CT.
\end{abstract}

\section{Resumen}

El carcinoma de las células colectoras de Bellini (CCB), es una variante rara y muy agresiva del carcinoma de células renales. Objetivos: Describir los hallazgos radiológicos de un caso de CCB y determinar su diagnóstico diferencial. Procedimientos básicos: Revisión de los trabajos publicados sobre este tumor y comparar los hallazgos radiológicos de nuestro caso con los de otros casos descritos. Hallazgos más importantes: Los CCB son tumores bien delimitados con alto componente hemorrágico, escaso realce interno y metástasis ganglionares. En el diagnóstico diferencial si la lesión presenta un crecimiento exofítico debería incluirse el carcinoma papilar, fundamentalmente la variante sarcomatoide y las lesiones benignas complejas (quistes complejos o hidatídicos). En cambio, si la lesión asocia un patrón infiltrante se tendrán en cuenta otras lesiones como el carcinoma medular o el linfoma. Conclusiones principales: En presencia de lesiones sólido-quísticas hipovasculares y adenopatías regionales debe incluirse el CCB en el diagnóstico diferencial.

Palabras clave: Carcinoma de células colectoras de Bellini; Tumor renal; Diagnóstico diferencial; RM; TC.

Sebastián C, et al.Carcinoma de los ductos colectores de Bellini: Presentación de un caso clínico y revisión del diagnóstico diferencial. Rev Chil Radiol 2017; 23(2): 48-54.

Correspondencia: Cristina Sebastián / crissebseb@gmail.com.

Trabajo recibido el 17 de enero de 2017. Aceptado para publicación el 12-junio de 2017.

\section{Introducción}

El carcinoma de las células colectoras de Bellini (CCB) es una variante rara y muy agresiva del carcinoma de células renales (CCR), constituyendo menos del $2 \%$ de los tumores renales ${ }^{1,2,3,4,5}$. Son tumores que se originan del segmento distal de los ductos colectores de Bellini de la médula renal, a diferencia de la mayoría de los carcinomas que se originan en 
el túbulo contorneado proximal ${ }^{6}$. Mancilla-Jiménez et $\mathrm{al}^{7}$ en 1976 describieron por primera vez la existencia de algunos carcinomas papilares que provenían de los túbulos colectores. Los síntomas de estos tumores son bastante inespecíficos, siendo la hematuria y el dolor lumbar, los síntomas más frecuentes ${ }^{8,9}$. Infrecuentemente, estos tumores cursan con síndrome constitucional o síntomas derivados de la compresión venosa $^{8}$. La edad de presentación es similar al resto de tumores renales, entre los 50 y 70 años, aunque algunos autores afirman que se originan en personas más jóvenes ${ }^{9,10}$. La detección de estas lesiones renales y de las metástasis linfáticas o viscerales se realiza mediante técnicas de imagen como la tomografía computarizada (TC) o la resonancia magnética (RM). Sin embargo, aunque permiten diagnosticar las lesiones más habituales como el carcinoma de células claras, no caracterizan adecuadamente los tumores atípicos como el carcinoma de los ductos de Bellini. Histológicamente, constituyen células con alto grado de atipia con patrones papilares, tubulares o nidos de células embebidas en un estroma desmoplásico. Un importante hallazgo diagnóstico es la presencia de anaplasia celular en los ductos colectores adyacentes al tumor ${ }^{11}$. Son tumores de muy mal pronóstico debido

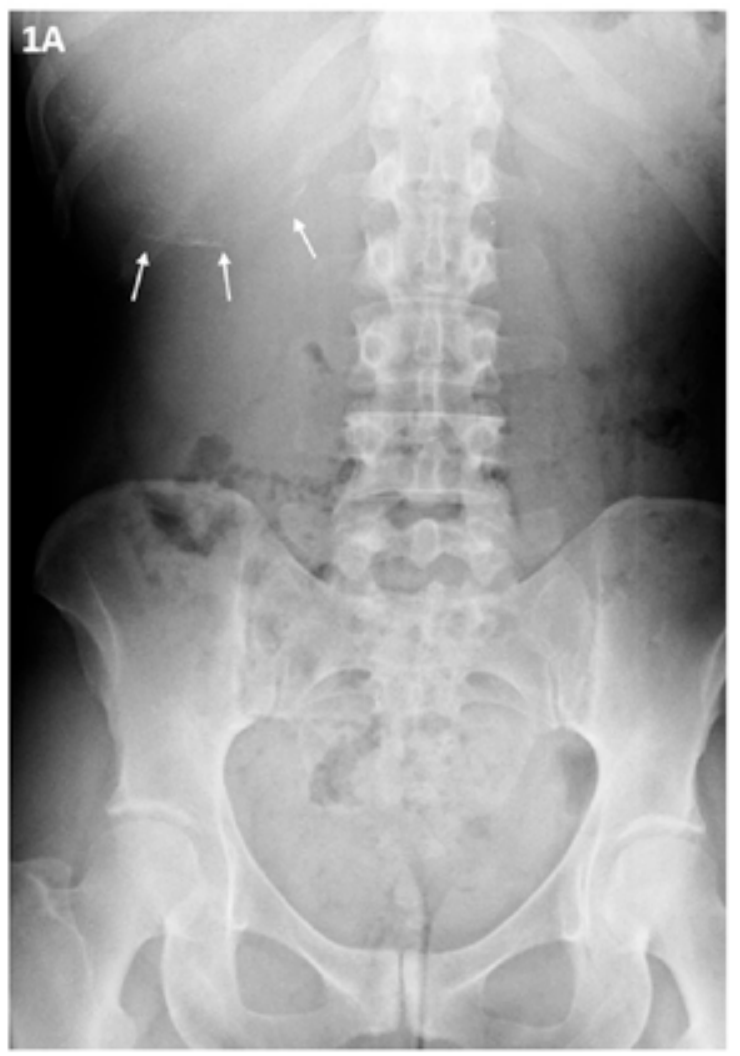

al diagnóstico inicial de enfermedad metastásica en la mayoría de pacientes y a la resistencia de estos tumores al tratamiento quimioterápico ${ }^{8,12}$. Presentamos a continuación un nuevo caso de carcinoma de los ductos de Bellini con adenopatías tumorales retroperitoneales y realizamos una revisión de la literatura.

\section{Presentación del caso}

Mujer de 49 años, intervenida hace un año por adenocarcinoma de mama (mastectomía bilateral y linfadenectomía axilar izquierda), en tratamiento con tamoxifeno, que acudió al servicio de urgencias por dolor en flanco derecho e infección de orina. La paciente había manifestado infecciones urinarias de repetición en los últimos 6 meses, pero no presentó hematuria ni síndrome constitucional. En el análisis de sangre destacó únicamente la elevación del marcador CA 125 de 124,8. Se solicitó una radiografía de abdomen y una ecografía abdominal urgentes (Figura 1), identificando en ecografía una voluminosa lesión dependiente del tercio superior cortical del riñón derecho y varias adenopatías retroperitoneales, con características de malignidad. Se completó el estudio con TC toraco-abdominal (Figura 2), confirmando la presencia de la masa renal derecha de contenido
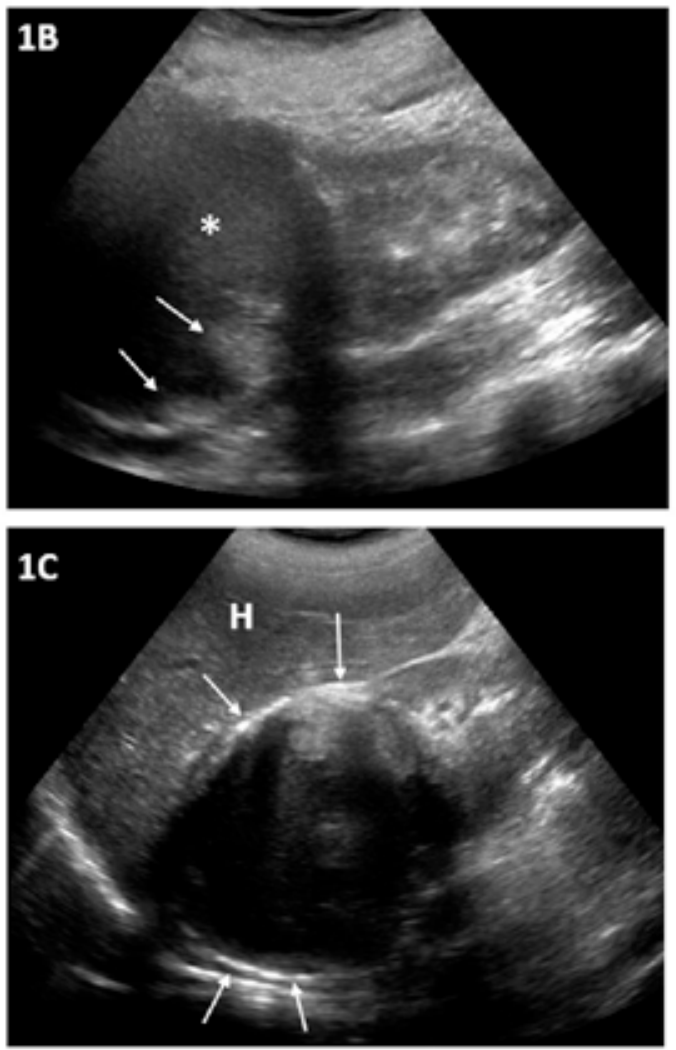

Figura 1. Radiografía simple de abdomen $(A)$ y ecografía abdominal (B y $C)$. $A$. Se muestra una imagen redondeada en hipocondrio derecho con calcificaciones lineales que delimitan su margen inferior (flechas en A) y otras calcificaciones redondeadas en el resto de la lesión. En ecografía se observa una lesión ovalada dependiente del polo superior del riñón derecho, de contenido líquido con ecos internos, probablemente hemorrágico (asterisco en B), con algún nódulo o coágulo parietal hiperecogénico (flechas en B) y calcificaciones gruesas parietales (flechas en C). Leyenda: H: hígado. 

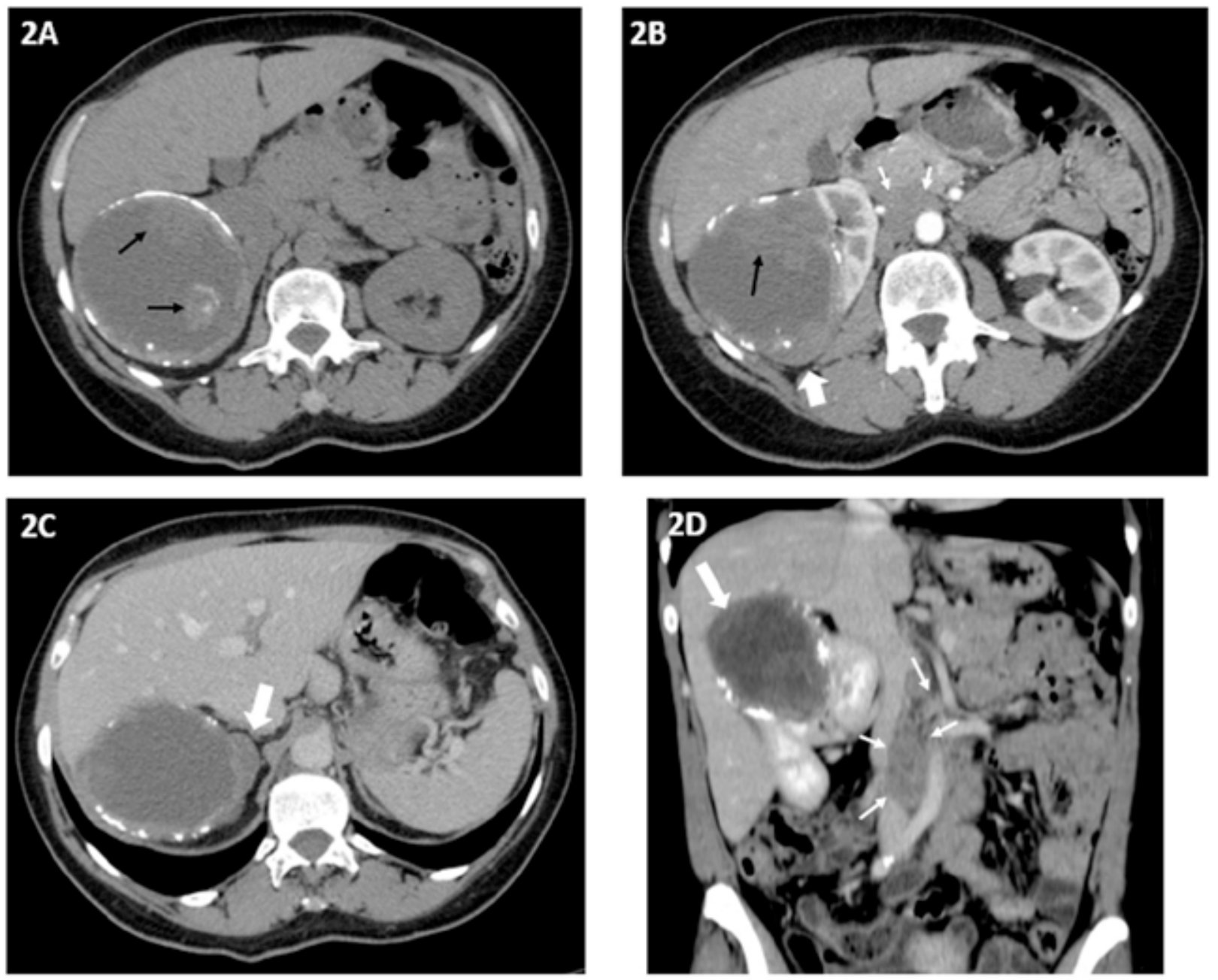

Figura 2. TC abdominal con secuencias basal $(A)$, arterial $(B)$ y portal $(C)$ tras la administración de contraste endovenoso en planos axiales y coronal en fase portal (D). Se muestra una lesión redondeada, de crecimiento exofítico, que distorsiona la morfología del riñón derecho (flecha gruesa en D), de paredes gruesas, parcialmente calcificadas y márgenes irregulares por la presencia de algunos nódulos sólidos (flechas gruesas en $B$ y C) que no muestran realce interno. Presenta un contenido líquido heterogéneo con áreas más densas (flechas en $A$ y B), de aspecto hemorrágico (flechas negras en $A$ y $B$ ). Se muestran adenopatías periaórticas y un conglomerado interaorto-cava (flechas finas en $B$ y $D$ ), de carácter tumoral.

líquido heterogéneo, de pared gruesa calcificada y algunos nódulos sólidos de morfología papilar, sin realce interno significativo. Se demostraron las adenopatías retroperitoneales tumorales, sin observar invasión vascular ni metástasis en otros órganos. Tampoco se detectaron signos de recidiva tumoral mamaria local ni en las cadenas linfáticas habituales. Al día siguiente, se realizó una RM abdominal (Figuras 3 y 4). Radiológicamente la lesión no cumplía criterios de los tumores renales habituales (carcinoma de células claras, oncocitoma o tumores uroteliales). Se intervino a la paciente una semana más tarde mediante nefrectomía radical derecha con extirpación de 4 de las adenopatías paraaórticas y del conglomerado interaortocava, sin poder extraerlas en su totalidad por su amplio contacto con los vasos. El servicio de anatomía patológica confirmó los hallazgos de carcinoma de los ductos colectores de Bellini con degeneración quística y metástasis en los 4 ganglios aislados. A la sección, el tumor estaba constituido por una cavidad quística con abundante contenido líquido necrohemorrágico y en la periferia se demostraron áreas sólidas nodulares, de aspecto papilar. Microscópicamente (Figura 5), el tumor presentaba una arquitectura túbulo-papilar con nidos periféricos de células atípicas, sin rasgos sarcomatoides. Se estableció un estadio pT3a pN1 según la clasificación AJCC TNM. 

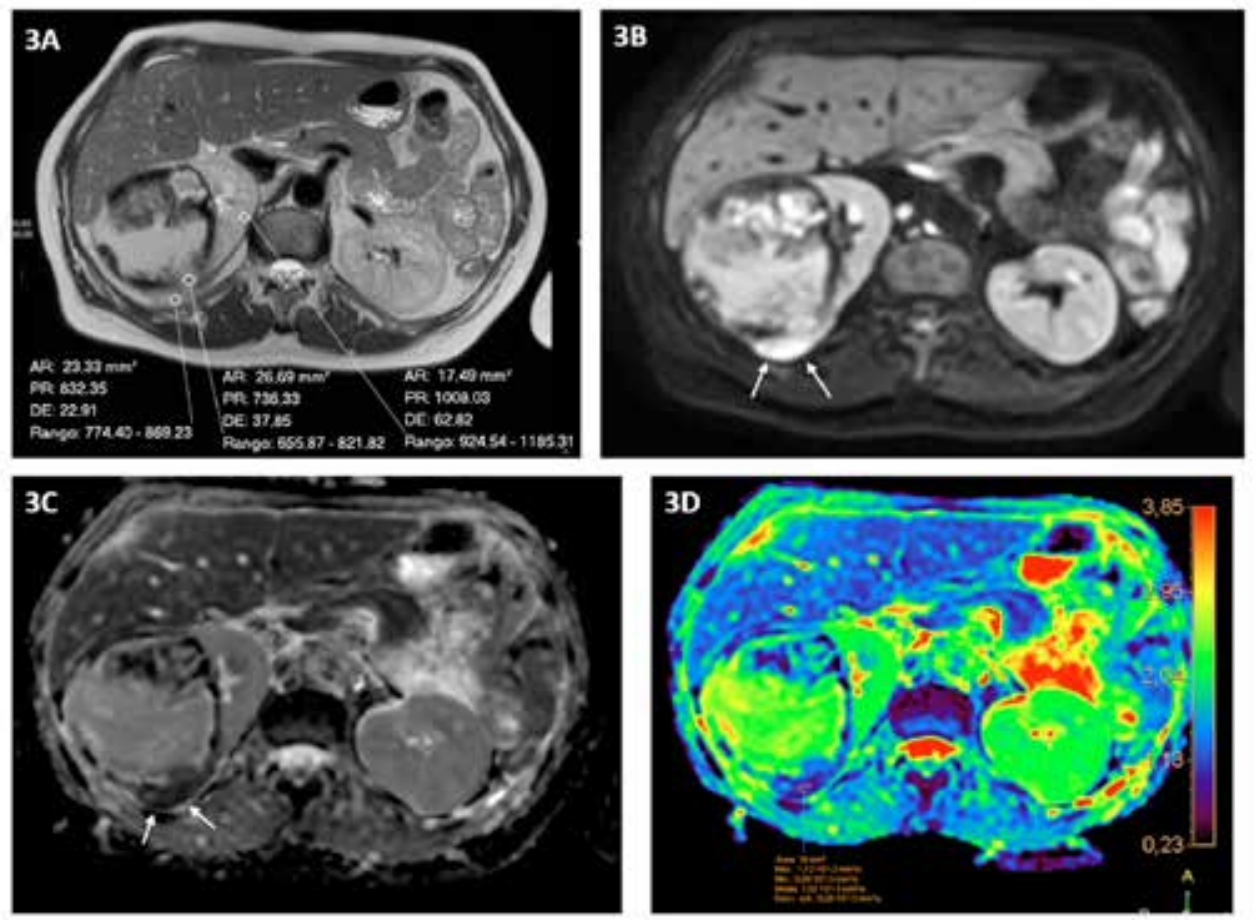

Figura 3. $R M$ abdominal con secuencias potenciadas en T2 (A), difusión con factor b 1000 (B) y mapa de CDA (C y D). La lesión presenta un contenido líquido heterogéneo de alta señal T2 en relación con presencia de contenido hemático, con calcificaciones periféricas hipointensas y un nódulo sólido en el margen posterior de la lesión, iso-hipointenso con el córtex renal. Se muestra el cálculo del índice T2 mediante la medición con ROI (region of interest) de la señal en la lesión tumoral respecto a la señal normal del córtex renal. Indice T2= señal T2 en la lesión/ señal T2 del córtex renal normal; 832,35/1008,03 y 736,33/1008,03=0,82 y 0,73. La lesión no mostraba restricción a la difusión, a excepción de un nódulo sólido (flechas en $B, C$ y $D$ ), con valores medios de CDA de $1,02 \times 10-3 \mathrm{~mm}^{2} / \mathrm{s}(D)$.
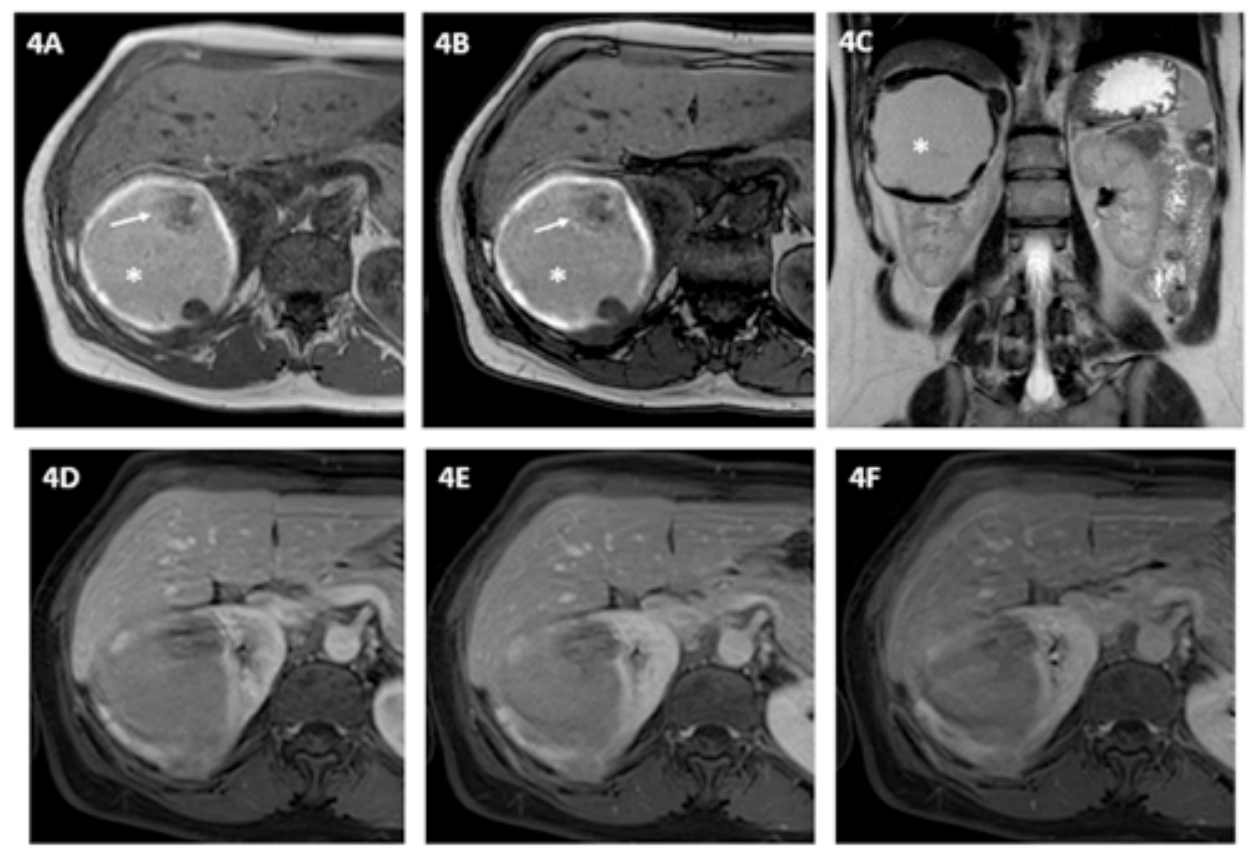

Figura 4. $R M$ abdominal con secuencias $T 1$ en fase y fuera de fase (A y B), T2 coronal (C) y secuencia dinámica tras la administración de contraste e.v. (en fases corticomedular, nefrográfica y retardada) ( $D$ - $F$ ). La lesión presenta contenido de alta señal en T1 y T2 (asteriscos en $A, B$ y C) con áreas más hipointensas heterogéneas (flechas en $A$ y B), en relación con contenido hemático en distintas fases, sin demostrarse cambios de señal en secuencias fase-fuera de fase que sugieran la presencia de componente graso microscópico o hemosiderina. En la secuencia dinámica pese a los artefactos de movimiento, se demuestra un sutil realce en el nódulo sólido tumoral del 22 y $8 \%$ en fases corticomedular y nefrográfica, respectivamente. 

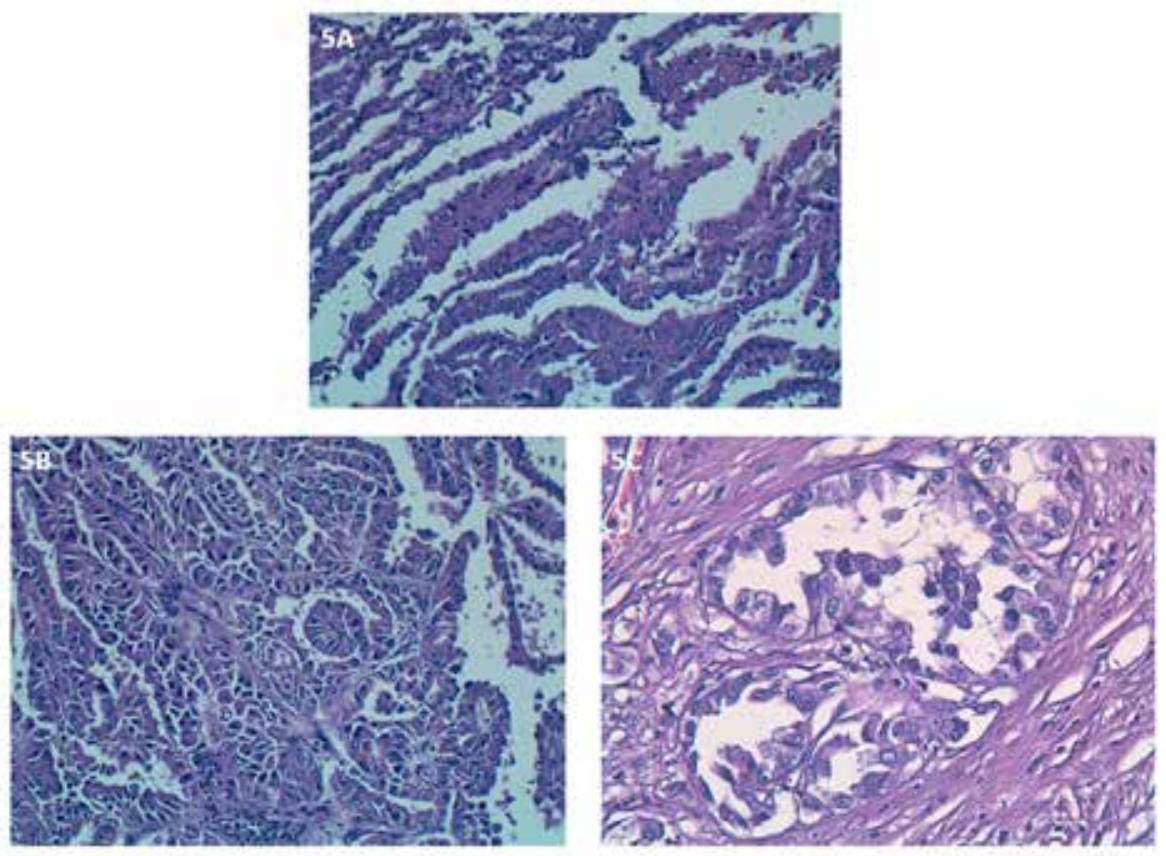

Figura 5. Estudio anatomopatológico del tumor con muestras de 20 aumentos $(A$ y $B)$ y 40 aumentos (C). El tumor muestra una degeneración quística extensa, con presencia de nidos tumorales conservados en la periferia. Presenta una arquitectura túbulo-papilar con algunos nidos sólidos, todo ello en un estroma desmoplásico. Las células son de talla media-grande, atípicas, con amplio citoplasma eosinófilo, pleomorfismo nuclear y nucleolo prominente.

\section{Discusión}

El carcinoma ductal de Bellini es un tumor muy poco frecuente y de mal pronóstico ${ }^{13}$. Se ha descrito una supervivencia al año del $50 \%$ y un $100 \%$ de mortalidad a los 3 años ${ }^{8}$. Los factores que determinan un mejor pronóstico de estos tumores son el bajo grado y un menor estadio tumoral ${ }^{14-16}$. Existen pocos casos de este tumor con crecimiento exofítico y afectación linfática ${ }^{6,8,9,17}$ y escasos estudios que describan el diagnóstico radiológico y su diagnóstico diferencial.

Los CCB son lesiones solitarias, de localización medular, patrón infiltrante preservando el contorno renal, con realce débil y heterogéneo, calcificaciones y composición quística como hallazgos más frecuentes ${ }^{1}$. Otros autores ${ }^{9}$ añaden que frecuentemente presentan márgenes mal definidos y mayor captación gammagráfica de Ga-67 comparativamente con los carcinomas transicionales o de células claras. Pichardt et $\mathrm{al}^{18}$, han descrito que los CCB de mayor tamaño pueden presentar un patrón más expansivo 0 exofítico, simulando un carcinoma de células claras. En nuestra paciente, el tumor era de gran tamaño (10 $\mathrm{cm}$ de eje mayor), con patrón exofítico cortical, de composición predominantemente hemorrágica, con alguna calcificación interna. La lesión se delimitaba por una pared gruesa calcificada y asociaba algunos nódulos sólidos de morfología papilar, extraparenquimatosos, que no mostraban realce significativo en TC ni en RM.

En varios trabajos ${ }^{19-22}$ se ha descrito que la TC y, fundamentalmente, la RM permiten caracterizar los tumores más habituales: carcinoma de células claras (70\% de incidencia) y los carcinomas cromófobos $(15 \%)$ y papilar $(5 \%)$. No obstante, existen otros subtipos mucho menos frecuentes como el CCB, el carcinoma medular renal, entre otros ${ }^{23,24}$, con hallazgos inespecíficos en técnicas de imagen. El realce tumoral sigue siendo una de las características más importantes para caracterizar las lesiones malignas. Se ha concluido en varios trabajos ${ }^{22,25}$ que los carcinomas de células claras realzan más intensamente $(125 \mathrm{UH}$ de valor medio en fase corticomedular y $80 \mathrm{UH}$ en la fase nefrográfica) que los carcinomas cromófobos (74UH de valor medio en fase corticomedular y $60 \mathrm{UH}$ en la fase nefrográfica) y los papilares (55UH de valor medio en fase corticomedular y $65 \mathrm{UH}$ en la fase nefrográfica). Algunos autores ${ }^{26}$, calcularon el porcentaje de realce relativo de estos tumores con la siguiente fórmula: [Intensidad de señal postcontrate - intensidad de señal precontraste /señal precontraste] x 100\%. Se demostró que los carcinomas de células claras presentaban mayor realce relativo $(205,6 \%$ en fase corticomedular y $247,1 \%$ en nefrográfica), comparativamente con los carcinomas cromófobos (109,9\%en fase corticomedular y $192,5 \%$ en nefrográfica) y papilares $(32,1 \%$ en fase corticomedular y $96,6 \%$ en nefrográfica). En nuestro caso, la lesión presentaba algunos nódulos papilares con sutil realce $(22 \%$ y $8 \%$ en fases corticomedular y nefrográfica, respecto a la secuencia basal). Al ser una lesión mayor de $3 \mathrm{~cm}$, 
con alto contenido hemorrágico-necrótico, de paredes gruesas parcialmente calcificadas y nódulos sólidos hipovasculares, con adenopatías retroperitoneales asociadas, se deben considerar el carcinoma papilar, principalmente la forma sarcomatoide y el CCB.

Los carcinomas papilares suelen ser corticales, encapsulados, de señal característicamente hipointensa en secuencias T2 de RM, y con contenido y realce homogéneos ${ }^{27-29}$. En algunos casos, pueden ser muy heterogéneos ${ }^{27}$ si presentan alto componente quístico o necrótico y en un $7 \%$ de los casos asocian calcificaciones internas. Los tumores papilares suelen ser tumores de bajo grado de malignidad salvo la forma sarcomatoide, que contienen más componente necrótico y producen adenopatías tumorales e invasión de la vena renal. La señal T2 de los nódulos sólidos de nuestro tumor era intermedia-baja, con índices T2 de 0,73-0,83 (Figura 3), similar a la obtenida en los tumores papilares: $0,67+0,2^{30}$. Sin embargo, los tumores papilares suelen ser hipointensos en la secuencia T1 en fase y ser hiperintensos en la secuencia T1 fuera de fase (Figura 4), por la presencia de hemosiderina, hallazgo no característico de los tumores CCB. No obstante, nuestro caso de CCB sería difícil de diferenciar del carcinoma papilar de tipo sarcomatoide por el tamaño tumoral, el alto contenido hemorrágico interno, la presencia de calcificaciones y los nódulos sólidos hipovasculares. Algunos autores han valorado la utilidad de la secuencia difusión ${ }^{31-34}$ para diferenciar los tumores más frecuentes. Wang et $\mathrm{al}^{34}$, encontraron que los carcinomas papilares $\left(1,1 \times 10-3 \mathrm{~mm}^{2} / \mathrm{s}\right)$ y los carcinomas cromófobos $(1,3$ $x 10-3 \mathrm{~mm}^{2} / \mathrm{s}$ ) tenían valores más bajos de coeficientes de difusión aparente (CDA) que los carcinomas de células claras $\left(1,8 \times 10-3 \mathrm{~mm}^{2} / \mathrm{s}\right)$, sin demostrar diferencias entre los papilares y cromófobos. Nuestra lesión no presentaba restricción a la difusión a excepción de un nódulo sólido, con valores de CDA similares al de los tumores cromófobos y papilares $\left(1,02 \times 10-3 \mathrm{~mm}^{2} / \mathrm{s}\right)$ como se muestra en la figura 3.

Entre las lesiones benignas, los quistes complejos (sobreinfectados o hemorrágicos) y los quistes hidatídicos tipos 3 y 4 de la clasificación de WHO-IGWE del $2003^{35,36,38}$ pueden presentar características similares al CCB, siendo fundamental la historia clínica. Es importante destacar que la mayoría de los casos de CCB son infiltrantes e intramedulares, y en el diagnóstico diferencial se deberían incluir otras lesiones más frecuentes: carcinoma urotelial, el carcinoma medular renal o el linfoma ${ }^{37,38}$.

\section{Conclusión}

Los carcinomas de células ductales de Bellini, son tumores muy raros, pero altamente agresivos. Se caracterizan por ser tumores bien delimitados con composición hemorrágica interna, escaso realce interno y metastatizan en ganglios linfáticos regio- nales. En el diagnóstico diferencial, deben incluirse las lesiones malignas más frecuentes en función del patrón de crecimiento tumoral (exofítico o infiltrante) y valorar la posibilidad de algunas lesiones benignas de composición compleja teniendo siempre en cuenta la historia clínica.

\section{Bibliografía}

1. Ciszewski S, Jakimów A, Smolska-Ciszewska B. Collecting (Bellini) duct carcinoma: A clinical study of a rare tumor and review of the literatura. Can Urol Assoc J 2015; (9-10): E589-593.

2. Abern MR, Tsivian M, Palascik TJ, Coogan CL. Characteristics and outcomes of tumors arising from the distal nephron. Urology 2012; 80: 140-146.

3. May M, Ficarra V, Shariat SF, Zigeuner R, Chromecki $\mathrm{T}$, Cindolo L, et al. Impact of clinical and histological parameters on disease specific survival in patients with collecting duct renal cell carcinoma: Development of a disease specific risk model. J Urol 2013; 90: 458-463.

4. Wright JL, Risk MC, Hotaling J, Lin DW. Effect of collecting duct histology on renal cell cancer outcome. J Urol 2009; 182: 2595-2599.

5. Carter MD, Tha S, Mcloughlin MG, Owen DA. Collecting duct carcinoma of the kidney: a case report and review of the literature. J Urol 1992; 147: 1096-1098.

6. Li Y, Jin L, Liu J, Chen D, Su Z, Zhou L, Chen D, Su $Z$, Zhou L, et al. Bellini's duct carcinoma: a report of two cases and a review of the literature. Oncology letters 2016; 11: 3839-3841.

7. Mancilla-Jiménez R, Stanley RJ, Blath RA. Papillary renal cell carcinoma: a clinical, radiologic, and pathologic study of 34 cases. Cancer 1976; 38: 2469-2480.

8. De Diego Rodríguez E, Pascual Soria C, Gutiérrez Baños JL, Martín García B, Hernández Rodríguez R, Portillo Martín JA, et al. Carcinoma de Bellini. Nuestra experiencia. Arch Esp de Urol 2000; 53: 611-616.

9. Ortiz Gorraiz M, Rosales leal JL, Tallada Buñuel M, Zibermann Morales S. Collecting duct carcinoma of the kidney with retroperitoneal lymph mass. Arch Esp Urol 2004; 57: 179-182.

10. Craver RD, Correa H, Crapanzano JP, Kumar SR, Gardner_RV. Renal collecting duct carcinoma in an 8-year-old child. Pediatr. Nephrol 1996; 10: 29.

11. Rumpelt, HJ, Störkel S, Moll, R., Schärfe, T, Thoenes W. Bellini duct carcinoma: further evidence for this rare variant of renal cell carcinoma. Histopathology 1991; 18: 115-122.

12. Jabbour R, Maddah J, Makhoul R, Mokbel E, Nasr F. Bellini duct carcinoma: two case reports. Labanese Med Jour 2013; 62: 241-244.

13. Singh I, Nabi G. Bellini duct carcinoma: review of diagnosis and management. Int Urol Nephrol 2002; 34: 91-95.

14. Otani M, Shimizu T, Serizawa H, Ebihara Y, Nagashima Y. Low-grade renal cell carcinoma arising from the lower nephron: a case report with immunohistochemical, histochemical and ultraestructural studies. Pathol Int 2001; 51: 954-60.

15. Farah R, Ben-Izhak O, Munichor M, Cohen H. Low-grade renal collecting duct carcinoma. A case report with histochemical, immunohistochemical, and ultrasound study. Ann Diagn Pathol 2005; 99: 46-48. 
16. Vázquez-Lavista LG, Uribe-Uribe N, Gabilondo-Navarro F. Collecting duct renal cell carcinoma: Two different clinical stages, two different clinical outcomes. Urol Int 2008; 81: 116-118.

17. De Diego E, Hernandez R, Martin B, Portillo Martín JA, Correas Gómez MA, Gutiérrez Baños J, et al. Masa retroperitoneal secundaria a Carcinoma de Bellini. Actas Urol Esp 1991; 23: 801.

18. Pichardt PJ, Siegel CL, McLarney JK. Collecting duct carcinoma of the kidney: Are imaging findings suggestive of the diagnosis? AJR Am J Roentgenol 2001; 176: 627-633.

19. Low G, Huang G, Fu W, Moloo Z, Girgis S. Review of renal cell carcinoma and its common subtypes in radiology. World J Radiol 2016; 8: 484-500.

20. Gurel S, Narra V, Elsayes KM, Siegel CL, Chen ZE, Brown JJ. Subtypes of renal cell carcinoma: MRI and pathological features. Diagn Interv Radiol 2013; 19: 304-311.

21. Vikram R, Ng CS, Tamboli P, Tannir NM, Jonasch E, Matin SF, et al. Papillary renal cell carcinoma: radiologic-pathologic correlation and spectrum of disease. Radiographics 2009; 29: 741-54; discussion 755-757.

22. Young JR, Margolis D, Sauk S, Pantuck AJ, Sayre J, Raman SS. Clear cell renal carcinoma: discrimination from other renal cell carcinoma subtypes and oncocitoma at multiphasic multidetector CT. Radiology 2013; 267: 444-453.

23. Edge SB et al. The American Joint Committee on Cancer: The 7th edition of the AJCC cancer staging manual and the future of TNM. Ann Surg Oncol. 2010; 17: 1471-1474.

24. Yoon SK, Nam KJ, Rha SH, Kim JK, Cho KS, Kim B, et al. Collecting duct carcinoma of the kidney: CT and pathologic correlation. Eur J Radiol 2006; 57: 453-460.

25. Lee-Felker SA, Felker ER, Tan N, Margolis DJ, Young JR, Sayre J, et al. Qualitative and quantitative MDCT features for differentiating clear cell carcinoma from other solid renal cortical masses. AJR 2014; 203: W16-24.

26. Sun MR, Ngo L, Genega EM, Atkins MB, Finn ME, Rofsky NM, et al. Renal cell carcinoma: dynamic contrast-enhanced MR imaging for differentiation of tumor subtypes-correlation with pathologic findings. Radiology 2009; 250: 793-802.
27. Couvidat C, Eiss D, Verkarre V, Merran S, Corréas J.-M. Méjean A, et al. Renal papillary carcinoma: Carcinoma papillary carcinoma: CT and MRI features. Diagnostic and interventional imaging 2014; 95: 1055-1063.

28. Pedrosa I, Chou MT, Ngo L, H Baroni R, Genega EM, Galaburda L, et al. MR classification of renal masses with pathologic correlation. Eur Radiol 2008; 18: 365375.

29. Pedrosa I, Alsop DC, Rofsky NM. Magnetic resonance imaging as a biomarker in renal cell carcinoma. Cancer 2009; 115: 2334-2345.

30. Oliva MR, Glickman JN, Zou KH, Teo SY, Mortelé KJ, Rocha MS, et al. Renal cell carcinoma: T1 and T2 signal intensity characteristics of papillary and clear cell types correlated with pathology. AJR Am J Roentgenol 2009; 192: 1524-1530.

31. Choi YA, kim CK, Park SY, Cho SW, Park BK. Subtype differentiation of renal cell carcinoma using diffusionweighted and blood oxygenation level-dependent MRI. AJR Am J Roentgenol 2014; 203: W78-84.

32. Goyal A, Sharma R, Bhalla AS, Gamanagatti S, Seth A, lyer VK, et al. Diffusion-weighted MRI in renal cell carcinoma: a surrogate marker for predicting nuclear grade and histological subtype. Acta Radiol 2012; 53: 349-358.

33. Lassel EA, Rao R, Shwenke C, Schoenberg SO, Michaely HJ. Diffusion-weighted imaging of local renal lesions: a meta-analysis. Eur Radiol 2014; 24: 241-249.

34. Wang $\mathrm{H}$, Cheng L, Zhang X, Wang D, Guo A, Gao Y, et al. Renal cell carcinoma: diffusion-weighted MR imaging for subtype differentiation at 3.0 T. Radiology 2010; 257: 135-143.

35. Kizildag B, Dagistan E, Gurel S, Alan C. CT and MRI findings of renal infestation by a huge active hydatid cyst. BMJ Case Rep 2013; 2013.

36. Pedrosa I, Saiz A, Arrazola J, Ferreirós J, Pedrosa CS. Hydatid disease: Radiologic and pathologic features and complications. Radiographics 2000; 20: 795-817.

37. Dimashkieh H, Choe J, Mutema G. Renal medullary carcinoma: a report of 2 cases and review of the literature. Arch Pathol Lab Med 2003; 127: 135-138.

38. Shetty S, Singh AC, Babu V. Primary renal lymphomaa case report and review of literature. J Clin Diagn Res 2016; 10: XD05-XD07. 